\title{
Calibration of CR-39 solid state nuclear track detector
}

\author{
P Wanabongse ${ }^{1 *}$, B Sola ${ }^{2}$, J Jamsangtong ${ }^{1}$ and S Rattanabussayaporn ${ }^{3}$ \\ ${ }^{1}$ Thailand Institute of Nuclear Technology, 16 Vibhavadi Rangsit Road, Chatuchak, Bangkok 10900, Thailand \\ ${ }^{2}$ Department of Nuclear Technology, Chulalongkorn University, Payathai Road, \\ Patoomwon Bangkok 10330, Thailand \\ ${ }^{3}$ Office of Atoms for Peace, 16 Vibhavadi Rangsit Road, Chatuchak, Bangkok 10900, Thailand \\ E-mail : paiwann@hotmail.com
}

\begin{abstract}
Nowadays there are increasing uses of SSNTD on scientific works in Thailand. Currently we are using SSNTD as an important tool for confirming active fault zones in a province in which a new nuclear research reactor has been proposed to come up. Soil gas radon was measured by both active and passive methods. In the latter case CR-39 SSNTD was installed in a PVC tube of $50 \mathrm{~cm}$ long by $5 \mathrm{~cm}$ in diameter. The tubes were placed in 50-cm deep holes lining perpendicular to the faults' trace for one week. In this paper we describe the method and the results on calibrating these detectors using a radon chamber and a NIST-traceable radium-226 standard source.
\end{abstract}

Keywords : Alpha-track detector, soil-gas radon, radon chamber, calibration.

PACS Nos. : $06.20 \mathrm{fb}, 81.65 . \mathrm{Cf}$

\section{Introduction}

CR-39 SSNTD has become the important tool for scientific works in Thailand, especially for radon gas measurement, for quite sometimes [1-4]. However, the use of SSNTD for exploring or confirming active fault zone has just started only recently, following the work of loannidesa [5]. These small numbers of application of SSNTD might be because the lack of a proper system for calibration. This paper reflects the emerging of one good calibration facility among the others [6,7].

Geologists have surveyed and published the geological map of the fault lines in Nakorn Nayok province, which is located in central Thailand at about 105 kilometres north-east of Bangkok. A new nuclear research centre had already established at Ongkarak, a district in this province, and a 10-MW nuclear research reactor has been proposed and planned to build there. Also during these recent years a medium-sized dam had been built in this province. Because of the awareness for the possibility of the earthquake, geologists are now busy confirming the active fault lines. A research 
group was then formed, in which we have taken part. Because radon anomalies have been confirmed to relate to active fault and earthquake in various parts of the world [5,8-10], radon gas mapping is the method preferred in the study.

\section{Methods}

We are involved in this research project on radon gas measurement using both active and passive devices. For active measurement we use $120-\mathrm{cm}$ long soil gas probes and the RAD7 radon gas detectors, both from Durridge Company Inc., USA. For passive measurement we use solid-state nuclear track detector, CR-39 plastic chip. A 1-cm by $1-\mathrm{cm}$ chip was attached under the screwed cap covered a PVC tube of 50-cm long by $5-\mathrm{cm}$ in diameter. Radon gas can enter into the tube via a polyethylene film covered the lower end. The tubes were placed in $50-\mathrm{cm}$ deep holes lining perpendicular to the faults' trace for one week.

We did the calibration for radon gas measurement using these CR-39 PVC-tube detectors. Because of the nature of large amount of soil gas radon we preferred to use an automated track counting method which is the RADOSYS system from Hungary. The exposures of CR-39 detectors to the known amount of radon concentrations were performed within a radon chamber measuring inside dimensions of $66.5-\mathrm{cm}$ deep by $66.5-\mathrm{cm}$ wide and $41.5-\mathrm{cm}$ tall. The chamber is made of $15-\mathrm{mm}$ thick acrylic sheets. The radon standard source model RN-2000A of PYLON Electronics Inc., Canada, was used. The NIST-traceable Ra-226 radioactivity of the source is $20.79 \mathrm{kBq}$. It had been modified to be operated as a flow-through radon gas source; the circulating gas loop can be connected to the chamber from the outside; the circulating pump is operated at 2.0 LPM for 15 minutes to deliver radon gas into the chamber.

Usually, three levels of radon concentration were used in a calibration. Firstly, radon inside the container was purged out by a pump at 2.0 LPM for 15 minutes. Then new radon was left to build up for a desired period of time, for example, one day, two days or three days. The activity of radon gas inside the container at anytime can be calculated by the equation :

$$
A_{\text {Radon }}=A_{\text {Radium }}{ }^{*}\left(1-\operatorname{Exp}\left(-\lambda_{\text {Radon }}{ }^{*} T\right)\right)
$$

where $A_{\text {Radon }}$ is activity of radon which will build up, $A_{\text {Radium }}$ is the activity of radium226 standard source, $\lambda_{\text {Radon }}$ is the decay constant of radon, and $T$ is build-up time.

Though we may estimate radon concentration inside the chamber from the eq. (1), actual concentration was measured by a pulse-counting ionization chamber, ATMOS $12 \mathrm{dpx}$ from Gammadata Instrument, Sweden. Radon concentrations inside and outside the chamber were continuously monitored using two ionization chambers. For each level of radon exposure the measuring time was usually taken longer than the exposure period of 24 hours. All exposed and controlled CR-39 chips were etched with $6.25 \mathrm{M} \mathrm{NaOH}$ solution for 4.5 hours at 90-degree celcius. Figure 1 shows three 


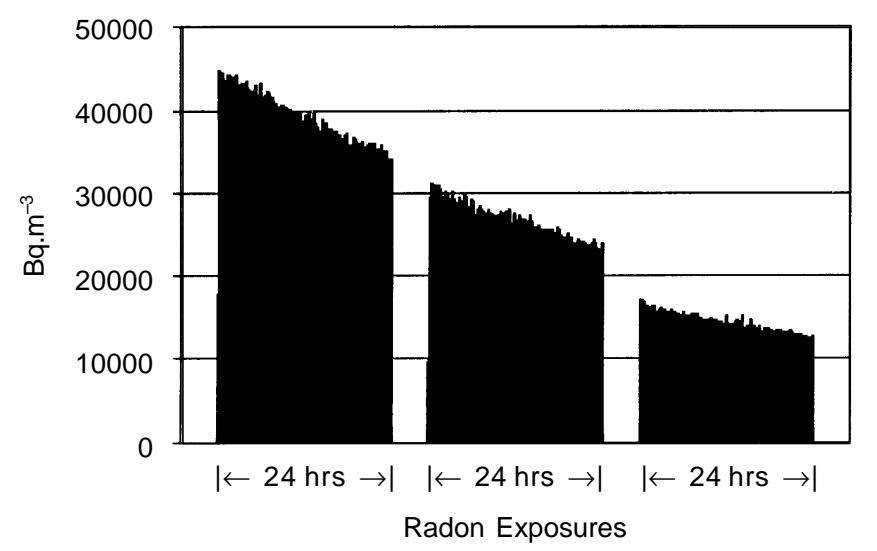

Figure 1. Three levels of actual radon concentration used for exposures.

measured radon concentrations inside the chamber obtained in the recent experiments.

\section{Results and discussion}

The calibration curve in Figure 2 shows relationship between track densities and radon concentrations, from nil up to $50,000 \mathrm{~Bq} \cdot \mathrm{m}^{-3}$. The sensitivity of CR-39 PVC-tube detector was calculated to be $0.31 \mathrm{track} /\left(\mathrm{cm}^{2} . \mathrm{kBq} \cdot \mathrm{h} / \mathrm{m}^{3}\right)$. This indicates that the CR-39 PVC-tube detector has very poor radon detection efficiency, comparing with the sensitivity value of 2.6 tracks $/\left(\mathrm{cm}^{2} . \mathrm{kBq} . \mathrm{h} / \mathrm{m}^{3}\right)$ stated by the manufacturer, using a specific radon diffusion cup.

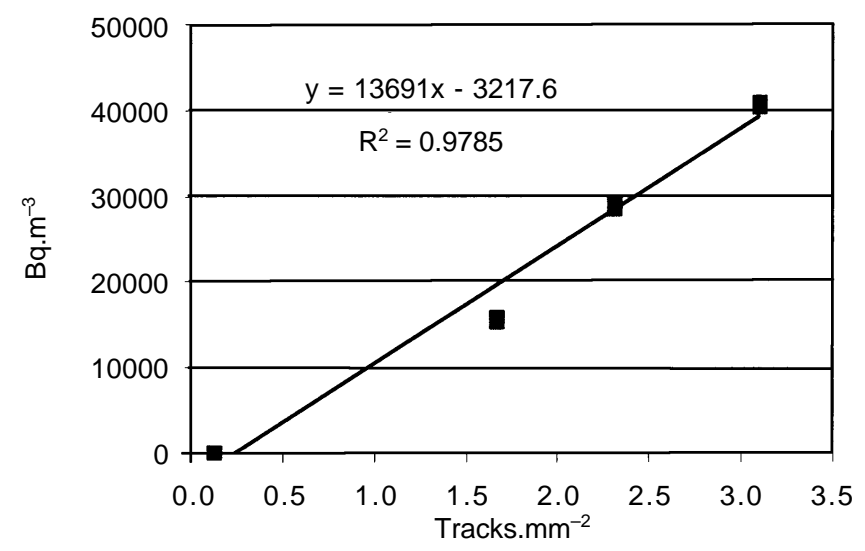

Figure 2. Calibration curve for radon measurement by CR-39 PVC-tube detectors.

An important source of error for calibration was the capability of the automated track counting system on registering most of the valid tracks. To minimize this error we have to strictly adhere to specification of the manufacturer for track etching and on setting of the proper reading parameters. However, the most important source of error 
was the fluctuation of track density registered by CR-39 PVC-tube detector. In order to have good average value of track density per radon exposure we put ten CR-39 PVC-tube detectors inside the chamber. The standard errors of track density for different radon exposures ranged from 23 to 39 percent.

Another small source of error was the measured radon concentration. We have tried to minimize this error by measuring radon concentration throughout the entire period of exposure, in order to have good average and error values. The measuring instrument, ATMOS $12 \mathrm{dpx}$, gave average radon level and the counting error. The counting error for high level of radon concentration is usually very low; for example, in our experiments the average radon concentration was $38,840 \mathrm{~Bq} \cdot \mathrm{m}^{-3}$ with the percentage counting error being only 0.15 , while for the average radon concentration of 14,215 Bq. $\mathrm{m}^{-3}$ the percentage counting error was 0.20 .

The range of radon concentrations prescribed for the calibration was adequate, since from the measurement of soil gas radon by active devices we have recorded soil gas radon in the study area ranging from a few-thousand to a maximum of over eightythousand Bq. $\mathrm{m}^{-3}$. However, we have avoided using too high radon levels for calibration because of the long-term performance of the radon monitoring equipment.

\section{Conclusions}

The current calibration practice using three radon exposure levels was satisfactory. The radon sensitivity obtained was not only the average value of three exposures and the control, but also the relationship between tracks counted and radon concentration, such as the saturation of track density, could be monitored. We planned to use this approach also for calibration of indoor radon measurement.

The leakage of radon from the chamber was not observed from the records of radon concentration monitored outside the chamber by another ATMOS $12 \mathrm{dpx}$ equipment operated during 24-hour exposure. The use of two radon monitors, one for the inside atmosphere of the chamber and another one for the outside, is both essential and beneficial; the leakage of radon can be of evidence, if any existed, and the operational safety can be assured. We will use this practice for further calibration operations.

\section{References}

[1] P Wanabongse, T Itthipoonthanakorn, Y Tumnoi, K Wattananikorn, S Sirijarukul, S Tokonami, W Zhuo, Y Yamada, T Ishikawa and S Bovornkitti J. Health Sci. 13414 (2004)

[2] P Wanabongse, T Harnwongse, A Sriratanabal, S Tokonami and S Bovornkitti Internal. Med. J. Thailand 20104 (2004)

[3] P Wanabongse, S Tokonami and S Bovornkitti Current Studies on Radon Gas in Thailand (Inter. Cong. Series 1276, Proc. of the Symp.) (eds.) T Sugahara, Y Sasaki, H Morishima, I Hayata, M Sohrabi and S Akiba 208 (2005) 
[4] K Wattananikorn, S Emharuthai and P Wanabongse Radiat. Meas. (2007), doi: 10.1016/j. radmeas. 2007.04.011

[5] K loannidesa, C Papachristodouloua, K Stamoulisa, D Karamanisa, S Pavlidesb, A Chatzipetrosb and E Karakalab App. Radiat. Isotopes 59205 (2003)

[6] R Shweikani and G Raja Radiat. Meas. 40316 (2005)

[7] G H Ahn and J Lee Nucl. Eng. and Tech. 37395 (2005)

[8] Y Yasuoka, T Ishii, S Tokonami, T Ishikawa, Y Narazaki and M Shinogi Radon anomaly related to the 1995 Kobe earthquake in Japan (Inter. Cong. Series 1276, Proc. of the Symp.) (eds.) T Sugahara, Y Sasaki, H Morishima, I Hayata, M Sohrabi and S Akiba 426 (2005)

[9] Chi-Yu King, Bi-Shia King, W C Evans and Wei Zhang App. Geochem. 11497 (1996)

[10] K Wattananikorn, M Kanaree and S Wiboolsake Radiat. Meas. 29593 (1998) 